\title{
Food and environmental behavior in times of the confinement by Covid-19, Apurímac, Peru
}

Rosa Huaraca Aparco', María del Carmen Delgado Laime², Fidelia Tapia Tadeo3, Fredy Taípe

Pardo4, Juan Alarcón Camacho 5

I José María Arguedas National University, Peru, rhuaraca@unajma.edu.pe

2 José María Arguedas National University, Peru, mcdelgado@unajma.edu.pe

3 José María Arguedas National University, Peru, ftapia@unajma.edu.pe

${ }^{4}$ José María Arguedas National University, Peru, ftaipe@unajma.edu.pe

${ }^{5}$ Technological University of the Andes, Peru, jalarconcamacho@yahoo.com

Correspondent author: rhuaraca@unajma.edu.pe

\begin{abstract}
Summary
Thechange in eating habits and responsible production systems leads to reduced environmental impact. The objective of this research was to study dietary and environmental behavior in university students in Andahuaylas province during the confinement of Covid-19. The study was cross-cutting through the use of data collected online through an anonymously resolved questionnaire, scheduled from July 18 to August 30, 2020 in the Apurímac-Peru region. In which 390 undergraduate students between the age of 18 and 28 participated. The questionnaire was divided into 03 sections:sociodemographic characteristics, dietary practices and environmental- related behavior during covid-19 confinement. In the study se found that $65.8 \%$ of students reported healthier dietary practices during covid-19confinement, in terms ofgender, women consistently consumed tubers (85.7\%), vegetables (73.5\%), fruits (61.2\%), Andean grains (49.0\%), compared to males who reported lower consumption. As for environmental behavior, respondents indicate that organic foodswere healthier and more environmentally friendly tolocal food.
\end{abstract}

KEY WORDS: Organic foods, Local products, Dietary practices, Healthy living.

\section{Introduction}

The Food and Agriculture Organization of the United Nations (FAO) recognizes that the Covid-19 pandemic has caused disruptions in food chains around the world, affecting both supply and demand for products (FAO., 2020). Compulsory confinement has influenced the population's food habits globally and dietary choice is one of the main points of influence that could make the food system more environmentally friendly, depending on the type of food and the amount of consumption; in this perspective it is important to explore about food diets during the confinement that has undoubtedly impacted on the different dimensions of the human being, with education at its different levels being one of the mostreferent. Highereducation in this region is no exception, university students in Andahuaylas face uncertainty and the economic crisis, which involves the pandemic, expressed in the lack of resources for their studies remotely, the fear of spreading, the stress that influences their academic performance and the likely change in food diets the environment.

The importance of highlighting good nutrition is critical to optimal human health; however, in recent decades eating habits have evolved into processed foods, such as refined meats, sugars and fat and fewer fruits, vegetables and whole grains which contributes to an increase in the incidence of diseases (Willet et al., 2019).

A food system should be one that contributes to global food and nutritional security in such a way that the economic, social and environmental pillars to generate thissecurity forfuture generations are not compromised (Ganesan, 2014). Sustainablediets are patterns of consumption and/or dietary choices that should be beneficial to human health, nutrition, environmental, social and economic areas. (Fischer and Garnett, 2016; World Health Organization, 2018). Dietary choices

have great relevance to climate change, providing information on which foods have a significant 
effectongreenhouse gasemissions (Gonzalesetal., 2020). dietslowin plant-based products and highin animal foods are responsible for the highestgreenhouse gas emissions (González-García eł al., 2018). In this regard, dietary changes have been proposed towards lower meat consumption, especially for medium and high income environments (Springmann et al., 2016), as well as environmentally friendly strategies such as prioritizing the consumption of non-air-transported productsorpromoting organic production (Jungbluthetal.,2000; Hallstrom Carlsson-Kanyamaet al., 2015).

It is essential to promote healthy eating behaviors to improve health outcomes (Ridderetal., 2017) and contain covid-19 disease and its consequences (Gasmi et al., 2020; Zhang et al., 2020; Kakodkaret al., 2020.) assessments of food, nutritional and environmental behaviors are critical to identifying comprehensive approaches to behavior management and developing strategies to improve students' food and environmental behaviors.

In accordance with the background, this research has been developed with the main objective of knowing the food and environmental behaviorsof university students during the confinement of Covid-19.

\section{Method}

Theresearch was developed through the application of a virtual surveyscheduled from August 18 to 30 , 2020, a period included within the confinement declared in Peru, involved 390 university students from the Professional School of Agroindustrial Engineering - Faculty of Engineering of the José María Arguedas National University. Prior to the resolution of the survey, participants gave their consent to participate in the study, using a digitally informed form.

The study was cross-designed, using data collected from the online survey questionnaire consisting of 30 questions about food consumption and environmental-related behaviors during Covid-19 confinement. The questionnaire was divided into 03 sections: sociodemographic characteristics, dietary practices and environmental-related behavior during Covid-19 confinement. Each student recorded the time they consumed the following food groups during Covid-19 confinement: Andean grains, legumes, vegetables, tubers, fruits, fried foods, dairy, sugary drinks, processed meat (burger, sausage, mortadella, salami, ham, chicken or sausage nuggets) and fresh meat. For statistical analysis, the two-way ANOVA was used adopting a 95\% confidence interval. Two variables were created to do this, the first variable that quantifies the frequencies of consumption of Andean grains, legumes, vegetables, tubers, fruits, fried foods, dairy, sugary drinks, processed meat (burger, sausage, mortadella, salami, ham, chicken nuggets or sausages); and fresh meat with four alternatives (constantly, once a week, once a month and very rarely). The collected sociodemographic variable is categorized into: gender: female - male; age and number of people living at home: $\leq 3$ people, 4-6 people and $\geq 7$ people. Statistical analysis was performed using the SPSS software program (V24,IBM corp)

\section{Results}

Frequency of food consumption in students.

The results of the food frequency questionnaire are shown in Figure 1, with a constant consumption of tubers (85.7\%), vegetables (73.5\%), fruit (61.2) and Andean grains (49.0\%).

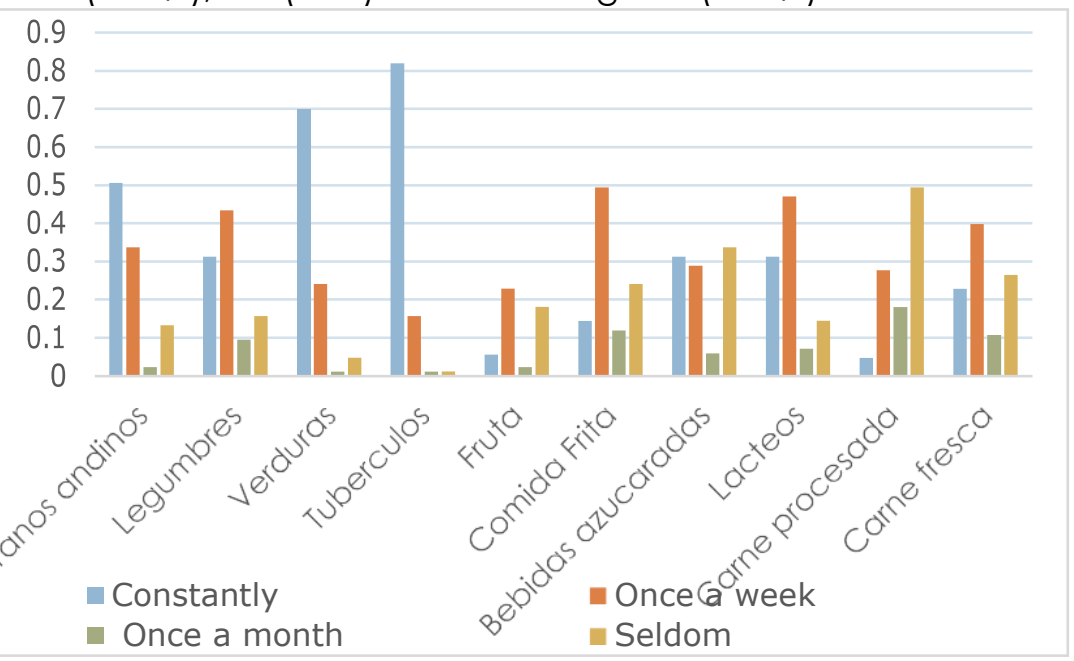

Figure 1. Frequency of food consumption during Covid-19 confinement 


\section{Sociodemographic features}

A total of 390 students participated in the study. Table 1. Sociodemographic characteristics are showntheaverageage of participantswas 18 to 29 years (98.8\%), gender (60\%) arewomenand (40\%) they're male. As for the number of family members it is shown that $(22.9 \%)$ are $\leq 3$ people, $(45.8 \%) 4-6$ people and (31.3\%) are $>7$ people at home.

Table 1. Sociodemographic features

\begin{tabular}{cc}
\hline Variables & Sample \% \\
\hline Sexo (No.390) & 59.8 \\
Woman & 40.2 \\
Wason & \\
Age & 98.8 \\
18 a 29 & 1.2 \\
29 a mas & \\
Family Members (No. & \\
124 ) & 22.9 \\
$\leq 3$ & 45.8 \\
$4-6$ & 31.3 \\
$>7$ &
\end{tabular}

\section{Consumption of food and students during covid-19 confinement according to sociodemographic characteristics. \\ Gender}

Gender results show that women had frequent high consumption of tubers and vegetables with a significance of $(p<0.005)$ during Covid-19 confinement. On the other hand, males also frequently consumed tubers, vegetables and fruits with a slight significance high in sugary drinks. Average food intake by gender confirms that women consumed significantly more tubers, vegetables, fruits and Andean grains during Covid-19 confinement. In Figure 2 the data are averages \pm SEM, comparison between groups using ANOVA.

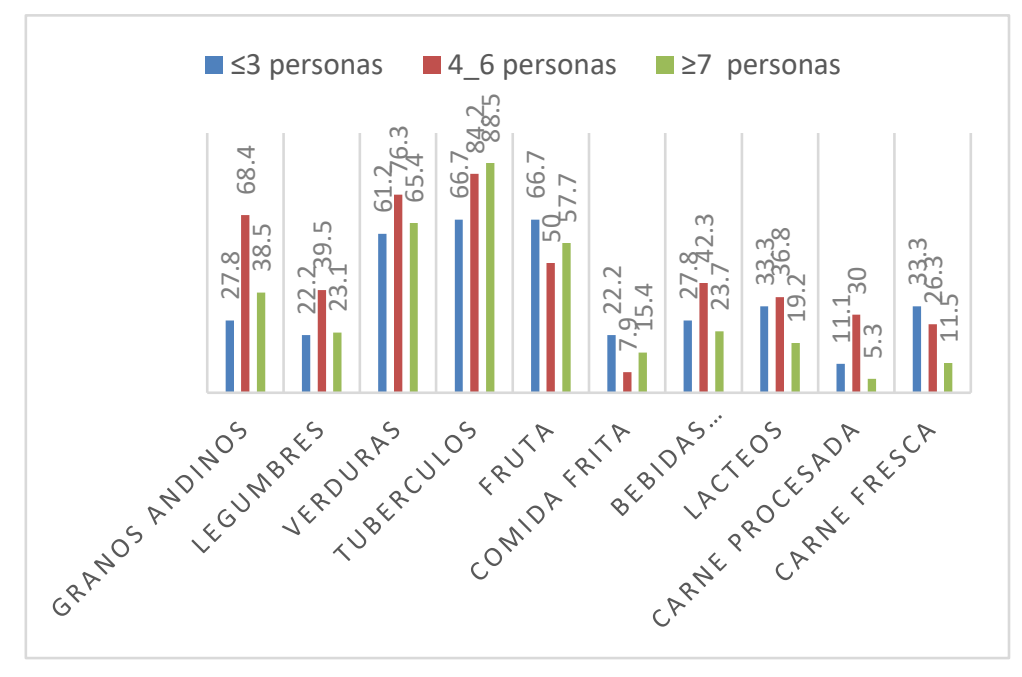

Figure 2. Comparison of average dietary intake between women and males during confinement.

It is also important to highlight changes in the pattern of fruit and vegetable consumption of students in this survey. $73 \%$ of women consumed vegetables daily compared to males with $63 \%$ during confinement. The results also show a greater preference for Andean grains, tuberculos, legumes and 
fruitsfoodgroups. Finding thatfamilieshave moretimetocookathome. Inaddition, WHO recommends groups of fruit, vegetable and legume foods as the best foods during prolonged self-quarantine. It was also found that fast food intake was drastically reduced in students during Covid-19 confinement.

\section{Number of family members in the household}

The data show that there was a difference in intake of sugary bdrunk foods and processed meat based on the number of family members. Group 4-6 people had a higher average intakeor sugary drink foods (Figure 2) compared to other groups in Table 2.

Only5,3\% of students in the $\leq 3$ people group and $11 \%$ of the $\geq 7$ group occasionally consumed processed meat food compared to $30 \%$ of the group 4-6 people Figure 3 . It should be noted that the lowestrate of adherence that belong to the weekly recommendation of intake of vegetables, sugary drinks and processed meat were given in those students who belong to the group $\geq 7$ people.

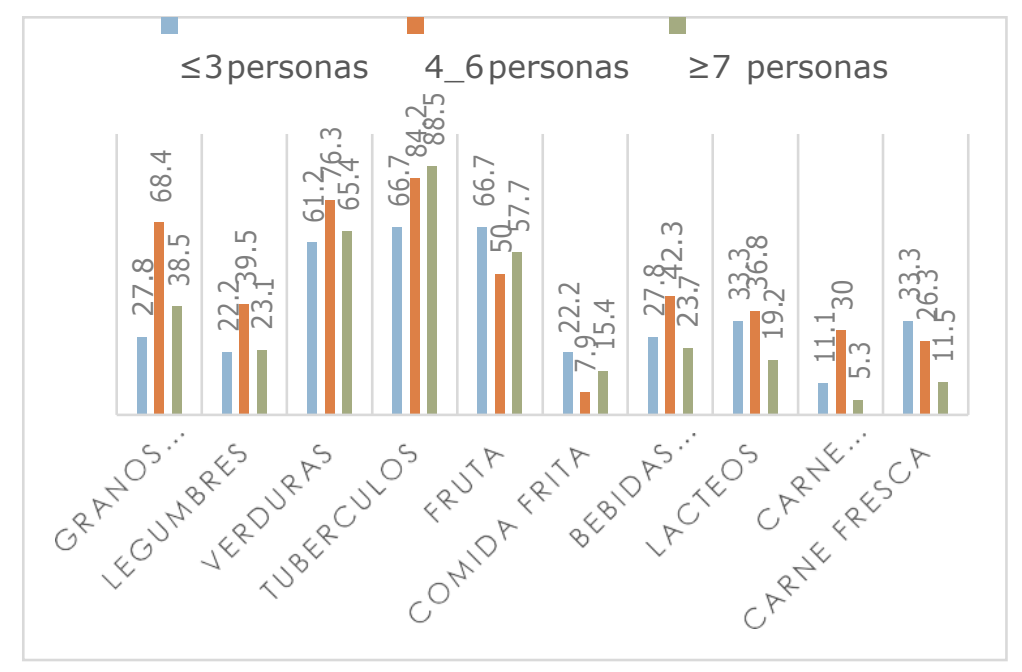

Figure 3. Average dietary intake between students during confinement by Covid-19 by family members (data are average comparisons between groups using paired ANOVA).

\section{Foods with less environmental impact}

According to the results in Figure 4. Respondents indicate that vegetables and fruits have less environmental impact on food groups meat, milk, processed foods and cereals. The percentages with the lowest score according to Figure 4 are shown for the group of foods such as milk and meat.

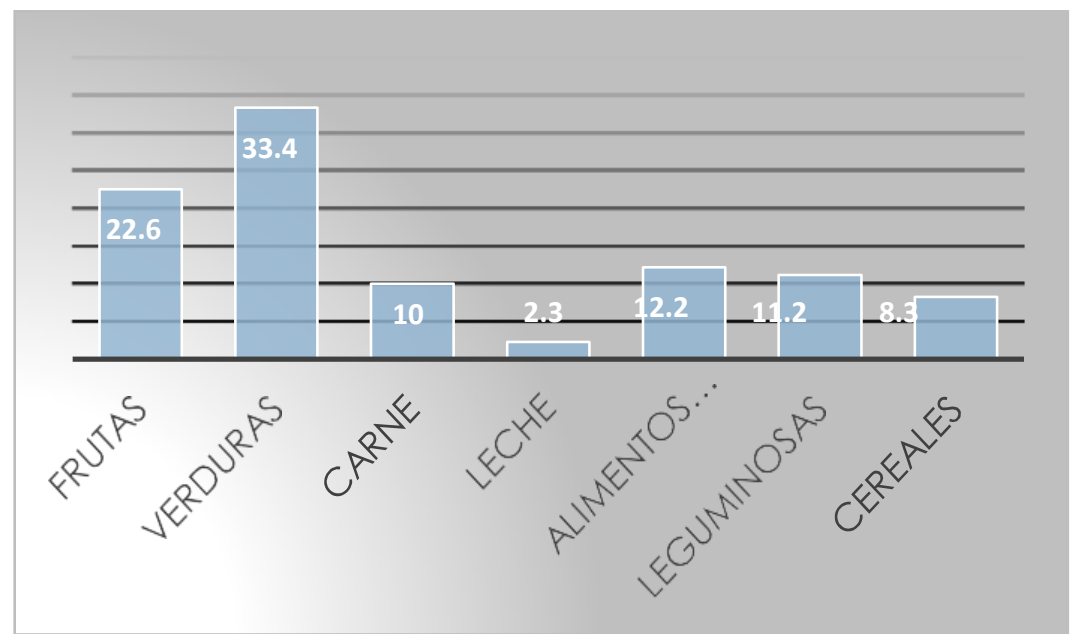

Figure 4. Foods with less environmental impact 


\section{Environmentally sustainable foods}

Based on results from the comparison of food groups as shown in Figure 5, students surveyed consider fruits, vegetables and legumes to be important for a sustainable diet with the environment. However, food groups andprocessed foods areconsidered unsusable diets with the environment.

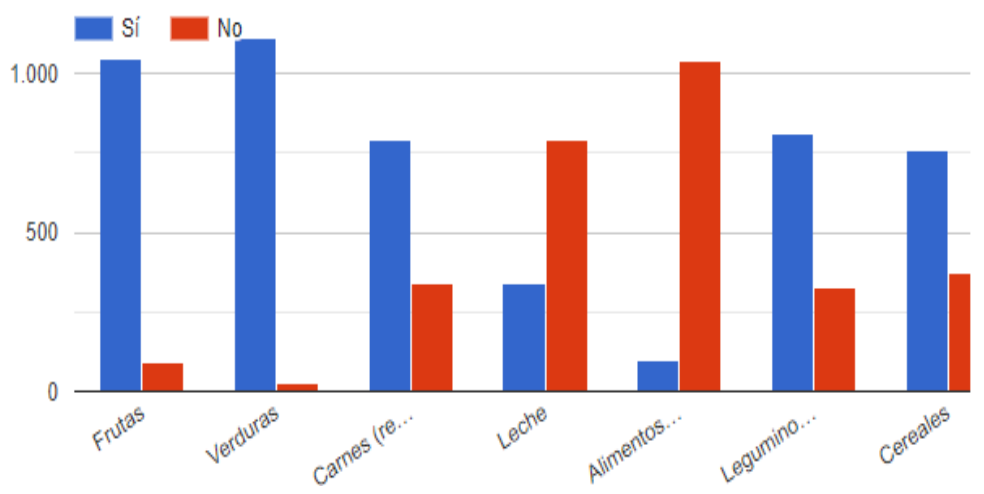

Figure 5. Food groups most important for a sustainable diet with the environment

\section{Comparison of organic and local food groups}

Figure 6 shows the comparison of organic and local foods, where $(87.0 \%)$ respondents were found to regard organic foods as environmentally friendly foods versus local foods.

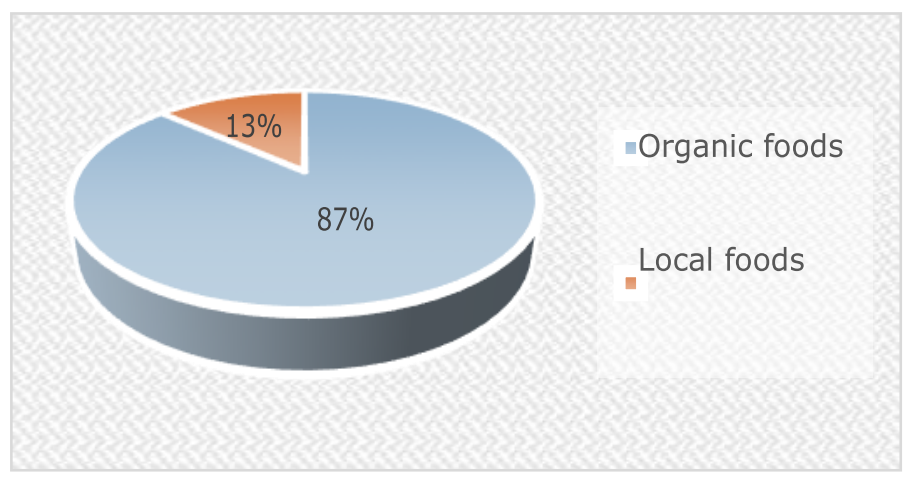

Figure 6. Comparison of organic and local foods

\section{Discussion}

The feeding of students during covid-19 confinement had an improvement due to the consumption of healthy and sustainable foods with the environment, these foods most commonly consumed are quinoa, kiwicha, tarwi, native potato, oca, olluco, eminently Andean and local products with high nutrient content and grown in the heights of the Andean mountains. $70 \%$ of students eat vegetablesdaily.

Confinement influences lifestyle, especially diet and physical activity. The World Health Organization and the Spanish Academy of Nutrition and Dietetics (2020) indicate that a healthy diet can help in the prevention and treatment of the disease (Lana R., 2020). Thus, recommendations for food and nutrition have been published during the period of population confinement, because there is a close relationship between the quality of a population's food, its health and the environment (Muscogiuri G., 2020). However, there is a likelihood that closer contact with family members and more home-cooked food due to covid-19 confinement in students could improve their knowledge, nutritional behaviors and environmental awareness, (Fulkerson J., 2017, Simmons D., 2012).

In relation to gender it was found that women consumed significantly more tubers, vegetables, fruits and Andean grains during confinement against male consumption. These results are consistent with studies on nutritional behaviors and gender differences (Grzymistawska M., 2020). Proper nutrition is considered a potential health factor. 
According to the foods with the greatest impact on the environment, dairy and meat are found in this group, so a healthier diet could have fewer environmental impacts (Tukker, et al., 2011). Dietary choice is one of the main points of influence that could make the food system more environmentally friendly, as well as dietary choice influences the entire food system as it depends on what the consumer eats (Gonzales et al., 2020). The environmental consequences arising from the choice of food such as climate change and the scarcity of water course should not be set aside, therefore, foranenvironmentally sustainable future attention mustbe paid to human diets and radical change is needed in our dietary choices to achieve food security and promote patterns of sustainable consumption. Seasonal and locally sourced foods are good for both health and the environment. Dietary choices are also directly influenced by the price offood (Believeet., 2013).

Therefore, sustainable diets are patterns of consumption and/or dietary choices that are beneficial to human health, nutrition, environmental, social andeconomic areas (Fischerand Garnett, 2016; World Health Organization,2018).

\section{Conclusions}

Our findings provide a first description of how Covid-19 confinement, impacting food consumption on college students, could have some subsequent positive impact on health. Apparently as a result of the pandemic, students had more tendency to change their diets by consuming foods such as tubers, vegetables, Andean grains and fruits, they have been significantly low in foods such as processed meat and dairy. The study shows the association between gender, age and family members at home with students' diets during Covid-19 confinement.Inthissense, itisimportant to understand the nutritional behavior of students during covid-19 confinement that will help public health authorities reform future policies on nutritional recommendations for university students that enable a better response in academic performance. As for environmental behavior, respondents indicate that organic foods were healthier and more environmentallyfriendly, however, theyindicate that they are expensive, arelationship wasfound between students' concern for the environment and their motivation to buy organic products compared to local value-added products. Students showed positive environmental attitudes during the confinement declared by Covid-19.

\section{Bibliographic Referencess}

FAO (2020). COVID-19 and risk to food supply chains: how to respond? http://www.fao.org/3/ca8388en/CA8388EN.pdf

Fischer and Garnett, (2016). Dishes, pyramids, planet: advances in healthy and sustainable national food patterns: an assessment of the state of the situation.

Fulkerson, J., Horning, M., Flattum, C., Draxten, M., Neumark, D., Gurvich, O., Garwick, A., Story, M., Kubik, MY. (2017). Family home food environment and personal and behavioral outcomes of parents and children related to the nutrition of healthy household offerings through the environment at mealtime (home) plus program: pag. 118. https://www.sciencedirect.com/science/article/abs/pii/S2212267217303465

FAO, Rome Italy. (2016). Food and Agriculture Organization of the United Nations(FAO). http://www.fao.org/land-water/databases-and-software/aquastat/en/

Green et al., (2013). The effect of rising food prices on food consumption: systematic review with metaaggression. BMJ , 346, p. f3703, 10.1136 / bmj.f3703. https://doi.org/10.1136/bmj.f3703.

Gonzalez, G., Rosemary, F., Green, F., Scheelbeek, F., Harris, D. (2020). Dietary recommendations in Spain: affordability and environmental sustainability? Journal of Cleaner Production, Volume254, ISSN0959-6526.https://doi.org/10.1016/j.jclepro.2020.120125.

Grzymis-awska, M., Puch, E., Zawada, A., Grzymis-awski, M. (2020). Do nutritional behaviors depend on biological sex and cultural gender? Adv. Clin. Exp. Medicine. , 29, 165-172. https://www.frontiersin.org/articles/10.3389/fpsyg.2015.00369/full

Gonzalez, F., Green, F., Scheelbeek, F., Harris, D. (2018). Carbon footprint and nutritional quality of different human diet options Sci. Total environment, pp. 77 - $94,10.1016$. https://doi.org/10.1016/j.scitotenv.2018.06.339

Gasmi, A., Noor, S., Tippairote, T., Dadar, M., Menzel, A. and Bjorklund, G. (2020). Individual risk management strategy and possible therapeutic options for the COVID-19 pandemic. Clin. Immunol, 215 , 108409. https://doi.org/10.1016/i.clim.2020.108409

Hallstrom, A., Kanyama, P., and B'rjesson. (2014). Environmental impact of dietary change: a systematic review. J. Clean. Page. 1 - 11, 10.1016. 
https://doi.org/10.1016/i.jclepro.2014.12.008

Jungbluth, N., Tietje, O. and Scholz, RW. (2000). Food purchases: impacts from the point of view of consumers investigated with a modular ACL. In t. J. LCA 5, 134 https://doi.org/10.1007/BF02978609

Lana, R., Coelho, F., Gomes, M., Cruz, O., Bastos, L., Villela, D., and Codeco, C.(2020). The emergence of the new coronavirus (SARS-CoV-2) and the role of timely and effective national health surveillance. You scoundrel. Page. 36.e00019620. https://www.scielosp.org/article/csp/2020.v36n3/e00019620/en/

Muscogiuri, G., Barrea, L., Savastano, S., Colao, A. (2020). Nutritional recommendations for CoVID- 19 quarantine. EUR. J. Cl.74, 850-851. https://www.nature.com/articles/s41430-020- 0635-2 s https://www.nature.com/articles/s41430-020-0635-2

World Health Organization. Information Sheet, (2018). A healthy diet produced sustainably. https://apps.who.int/iris/bitstream/handle/10665/278948/WHO-NMH-NHD-18.12eng.pdf?ua=1

Kakodkar, P., Kaka, N., Baig, M. (2020). A comprehensive review of the literature on clinical presentation and management of pandemic coronavirus disease 2019 (COVID-19). Cureus, 12 , e7560. https://doi:10.7759/cureus.7560

Ridder, D., Kroese, F., Evers, C., Adriaanse, M., Gillebaart, M. (2017). Healthy diet: impact on health, prevalence, correlates and interventions. Psychol. Page. 32 , 907-941. https://doi:10.7759/cureus.7560

Simmons, D.; Chapman, G.(2012) The importance of home cooking in families. Br. Food J. $114,1184-$ 1195. https://www.emerald.com/insight/content/doi/10.1108/00070701211252110/fu II/html

Springmann and Col. (2016). Scarborough. Analysis and valuation of cobeneficios for the health and climate change of Proc dietary change. Natl. Akkad. Sci.113, pp. $4146-4151,10.1073$ / pnas.1523119113.https://doi.org/10.1073/pnas.1523119113

Tukker, R., Goldbohm, A., Verheijden., Kleijn, R., Wolf, O., and Perez, I. (2011). Environmental impacts of changes towards healthier diets in Europe. Ecological Economics. Volume 70, Issue 10, Pages 1776-1788, ISSN 0921-8009. https://doi.org/10.1016/i.ecolecon.2011.05.001

Willetetal., (2019). Food in the Anthropoccene: the EAT-Lancet Commission on Healthy Diets from Sustainable Food Systems The Lancet, 393 ( 10170 ), pp. 447 - 492. https://doi.org/10.1016/S0140-6736(18)31788-4

Ganesan, (2014). HLPE Food Loss and Waste in the Context of Sustainable Food Systems. Report of the High-LevelPanel of FoodSecurity and Nutrition Experts (HLPE) of the Committee on Global Food Security, FAO, Rome. http://www.fao.org/3/a-i3901e.pdf. 